University of Wollongong

Research Online

Australian Institute for Innovative Materials -

Papers

Australian Institute for Innovative Materials

$1-1-2013$

Crystal growth, structure and thermal properties of noncentrosymmetric single crystals $\mathrm{PrCa} 4 \mathrm{O}(\mathrm{BO3}) 3+$

\author{
Fapeng Yu \\ Shandong University \\ Shujun Zhang \\ The Pennsylvania State University, shujun@uow.edu.au \\ Xiufeng Cheng \\ Shandong University \\ Xiulan Duan \\ Shandong University \\ Tingfeng Ma \\ Ningbo University
}

See next page for additional authors

Follow this and additional works at: https://ro.uow.edu.au/aiimpapers

Part of the Engineering Commons, and the Physical Sciences and Mathematics Commons

Research Online is the open access institutional repository for the University of Wollongong. For further information contact the UOW Library: research-pubs@uow.edu.au 


\title{
Crystal growth, structure and thermal properties of noncentrosymmetric single crystals PrCa4O(BO3)3+
}

\author{
Abstract \\ Noncentrosymmetric praseodymium calcium oxyborate single crystals, $\mathrm{PrCa} 4 \mathrm{O}(\mathrm{BO}) 3$ ( $\mathrm{PrCOB})$, were \\ grown by the Czochralski technique. The monoclinic unit cell parameters were found to be $a=8.177 \AA, b$ \\ $=16.157 \AA, c=3.629 \AA$ and $Z=2$ with space group $\mathrm{Cm}$. Crystal density was measured using the \\ Archimedes method, being on the order of $3.47 \mathrm{~g} \mathrm{~cm}-3$. Thermal properties of PrCOB were investigated, \\ where the specific heat was found to be $0.63 \mathrm{~J} \mathrm{~g}-1{ }^{\circ} \mathrm{C}-1$ at room temperature, increasing to $0.85 \mathrm{~J} \mathrm{~g}-1^{\circ} \mathrm{C}-1$ \\ at $700^{\circ} \mathrm{C}$. The thermal expansion coefficients were measured to be $\alpha 11=7.99, \alpha 22=4.90$ and $\alpha 33=9.46$ \\ $\left(10-6 /{ }^{\circ} \mathrm{C}\right)$, respectively. In addition, thermal diffusivity $\lambda 22$ and thermal conductivity $\mathrm{K} 22$ as a function of \\ temperature were studied, where $\lambda 22$ was observed to decrease from 0.89 to $0.58 \mathrm{~mm} 2 \mathrm{~s}-1$, while $\mathrm{k} 22$ \\ was found to maintain the same value, being $\sim 1.90 \mathrm{~W} \mathrm{~m}-1^{\circ} \mathrm{C}-1$ over the temperature range of $20-700^{\circ} \mathrm{C}$. \\ 2013 The Royal Society of Chemistry.
}

\section{Keywords}

properties, thermal, structure, single, growth, crystal, bo3, 3, noncentrosymmetric, crystals, prca4o

Disciplines

Engineering | Physical Sciences and Mathematics

\section{Publication Details}

Yu, F., Zhang, S., Cheng, X., Duan, X., Ma, T. \& Zhao, X. (2013). Crystal growth, structure and thermal properties of noncentrosymmetric single crystals PrCa4O(BO3)3+. CrystEngComm, 15 (26), 5226-5231.

\section{Authors}

Fapeng Yu, Shujun Zhang, Xiufeng Cheng, Xiulan Duan, Tingfeng Ma, and Xian Zhao 


\section{CrystengComm}
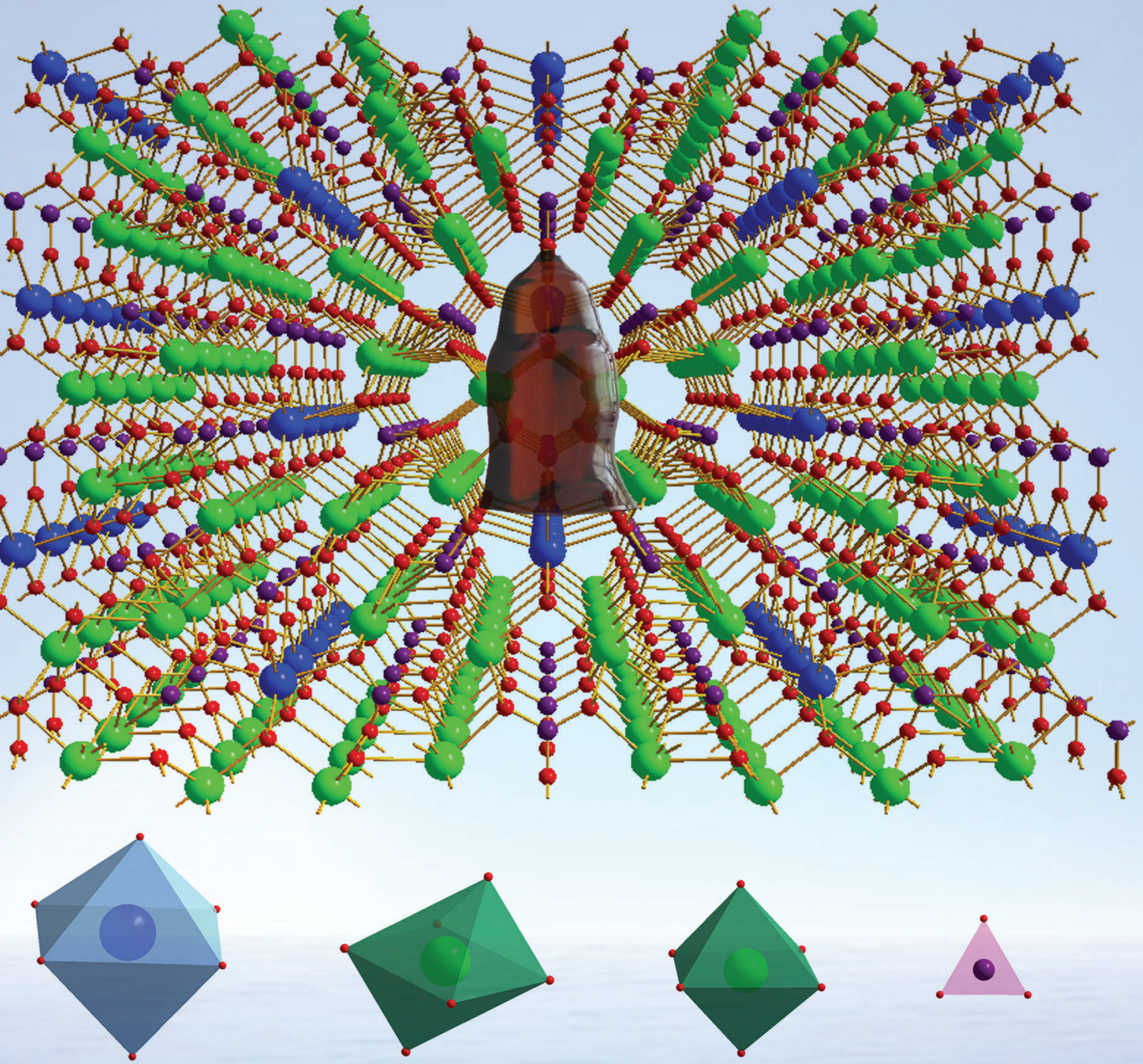

$\mathrm{Re}-\mathrm{O}$

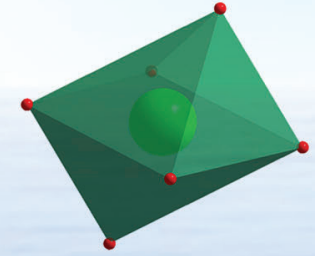

Ca1-O

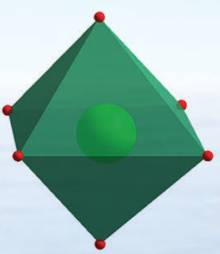

$\mathrm{Ca} 2-\mathrm{O}$

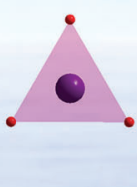

B-O 
Cite this: CrystEngComm, 2013, 15, 5226

Received 7th January 2013, Accepted 7th February 2013

DOI: $10.1039 /$ c3ce00024a

www.rsc.org/crystengcomm

\section{Crystal growth, structure and thermal properties of noncentrosymmetric single crystals $\mathrm{PrCa}_{4} \mathrm{O}\left(\mathrm{BO}_{3}\right)_{3} \dagger$}

\author{
Fapeng $\mathrm{Yu}^{\text {a }}$ Shujun Zhang, ${ }^{\text {tb }}$ Xiufeng Cheng, ${ }^{a}$ Xiulan Duan, ${ }^{a}$ Tingfeng $\mathrm{Ma}^{\mathrm{c}}$ \\ and Xian Zhao*a
}

\begin{abstract}
Noncentrosymmetric praseodymium calcium oxyborate single crystals, $\mathrm{PrCa}_{4} \mathrm{O}\left(\mathrm{BO}_{3}\right)_{3}(\mathrm{PrCOB})$, were grown by the Czochralski technique. The monoclinic unit cell parameters were found to be $a=8.177 \AA$, $b=$ $16.157 \AA, c=3.629 \AA$ and $Z=2$ with space group $C m$. Crystal density was measured using the Archimedes method, being on the order of $3.47 \mathrm{~g} \mathrm{~cm}^{-3}$. Thermal properties of PrCOB were investigated, where the specific heat was found to be $0.63 \mathrm{~J} \mathrm{~g}^{-1}{ }^{\circ} \mathrm{C}^{-1}$ at room temperature, increasing to $0.85 \mathrm{~J} \mathrm{~g}^{-1}{ }^{\circ} \mathrm{C}^{-1}$ at $700{ }^{\circ} \mathrm{C}$. The thermal expansion coefficients were measured to be $\alpha_{11}=7.99, \alpha_{22}=4.90$ and $\alpha_{33}=9.46\left(10^{-6} /{ }^{\circ} \mathrm{C}\right)$, respectively. In addition, thermal diffusivity $\lambda_{22}$ and thermal conductivity $\kappa_{22}$ as a function of temperature were studied, where $\lambda_{22}$ was observed to decrease from 0.89 to $0.58 \mathrm{~mm}^{2} \mathrm{~s}^{-1}$, while $\kappa_{22}$ was found to maintain the same value, being $\sim 1.90 \mathrm{~W} \mathrm{~m}^{-1}{ }^{\circ} \mathrm{C}^{-1}$ over the temperature range of $20-700{ }^{\circ} \mathrm{C}$.
\end{abstract}

\section{Motivation}

Rare-earth calcium oxyborate crystals $\mathrm{ReCa}_{4} \mathrm{O}\left(\mathrm{BO}_{3}\right)_{3}(\mathrm{Re}=$ rare earth element, abbreviated as ReCOB) with monoclinic phase in space group $\mathrm{Cm}$, are multifunctional materials. These crystals possess the merits of none phase transformation, chemical stable and easy to polish. Moreover, due to their noncentrosymmetric structure characteristics, extensive studies have been carried out for nonlinear optical applications, such as second- and third-harmonic generation, and laser frequency-doubling devices in the last two decades. ${ }^{1-7}$

To date, several kinds of ReCOB crystals $(\mathrm{Re}=\mathrm{Er}, \mathrm{Y}, \mathrm{Gd}, \mathrm{Sm}$, $\mathrm{Nd}$ and La) grown by the Czochralski $(\mathrm{Cz})$ pulling technique have been reported. ${ }^{3-7}$ Other ReCOB crystals, e.g. YbCOB, TbCOB and EuCOB etc., are very difficult to grow using traditional $\mathrm{Cz}$ method, due to the noncongruent melting or narrow congruent melting region. Recently, electro-elastic properties of ReCOB type crystals, including YCOB, GdCOB, NdCOB and LaCOB, have been extensively investigated. ${ }^{8-15}$ Among these crystals, NdCOB crystals were reported to possess a relatively high surface acoustic wave (SAW) coupling factor $\left(k^{2}=0.8 \%\right)$ and low linear temperature coefficient of delay (TCD) (close to zero), ${ }^{16}$ while YCOB crystals were observed to

\footnotetext{
${ }^{a}$ State Key Lab of Crystal Materials and Institute of Crystal Materials, Shandong University, Jinan, 250100, P. R. China. E-mail: fapengyu@sdu.edu.cn; Fax: +86 531 88364864; Tel: +8653188364068

${ }^{b}$ Materials Research Institute, Pennsylvania State University, University Park, PA, 16802, USA. E-mail: soz1@psu.edu; Fax: +1-814-865-7173; Tel: +1-814-863-2639 ${ }^{c}$ Piezoelectric Device Laboratory, School of Engineering, Ningbo University, Ningbo, 315211, P. R. China

$\dagger$ CCDC reference number 917976. For crystallographic data in CIF or other electronic format see DOI: $10.1039 / \mathrm{c} 3 c e 00024 \mathrm{a}$
}

show high stability of electromechanical properties at elevated temperatures, ${ }^{14,15}$ and explored for high temperature accelerometer applications. ${ }^{17-19}$ In previous reports, it has been revealed that the piezoelectric coefficient $d_{26}$ and electromechanical coupling factor $k_{26}$ increase with increasing rare-earth ionic radius, the relationship between crystal structure and piezoelectric properties was established, where the distortions of $\mathrm{Re}-\mathrm{O}$ and $\mathrm{Ca}-\mathrm{O}$ octahedra in ReCOB crystals were believed to account for the enhancement of piezoelectric coefficient $d_{26}{ }^{20-22}$ However, among ReCOB crystals, reports on the growth and structure of PrCOB crystals are very limited. ${ }^{20,22}$ In addition, high temperature thermal properties of PrCOB crystal have not been reported yet, which are important for high temperature (piezoelectric) device design.

In this work, $\mathrm{Cz}$ growth of PrCOB crystals was studied and the crystal structure was analyzed. Furthermore, thermal properties, including the specific heat, thermal diffusivity and thermal conductivity of PrCOB crystals at room temperature and elevated temperatures were measured and compared with its analogues, for potential high temperature applications.

\section{Growth of PrCOB single crystals}

Starting materials for PrCOB crystal growth were high purity (99.99\%) $\mathrm{CaCO}_{3}, \mathrm{Pr}_{6} \mathrm{O}_{11}$ and $\mathrm{H}_{3} \mathrm{BO}_{3}$ powders. They were weighed according to the nominal composition. Considering the evaporation of $\mathrm{B}_{2} \mathrm{O}_{3}$ during the growth process, an excess of $\mathrm{H}_{3} \mathrm{BO}_{3}(1.0 \%-1.5 \%)$ was added to the starting components, which was found to benefit the crystal growth. The starting materials were fully mixed, and then pressed into tablets and calcined at $1000{ }^{\circ} \mathrm{C}$ for $10 \mathrm{~h}$, to decompose $\mathrm{H}_{3} \mathrm{BO}_{3}$ and $\mathrm{CaCO}_{3}$ 
completely. After calcination, the powder was ground, mixed and pressed into pieces again, and then sintered at $1100{ }^{\circ} \mathrm{C}$ for $10 \mathrm{~h}$ to synthesize polycrystalline PrCOB compound for crystal growth. Crystals were grown by the conventional $\mathrm{Cz}$ method in a nitrogen atmosphere containing $4 \%$ oxygen by volume. An iridium crucible with $70 \mathrm{~mm}$ in diameter and $50 \mathrm{~mm}$ in height was used and heated by a $2 \mathrm{kHz}$ low radio-frequency furnace (TDL-J40 single crystal growth furnace). The temperature was precisely controlled by using an EU-ROTHERM 818 controller/ programmer with a precision of $\pm 0.5{ }^{\circ} \mathrm{C}$. The charge was melted and then kept $50{ }^{\circ} \mathrm{C}$ above the melting point for at least $2 \mathrm{~h}$, in order to get rid of the remaining gas bubbles and achieve homogeneous melt prior to the crystal growth.

An $<010>$-orientated $\mathrm{YCa}_{4} \mathrm{O}\left(\mathrm{BO}_{3}\right)_{3}$ (YCOB) crystal bar was used as a seed to initiate PrCOB crystal growth from the melt. The seed was introduced into the melt at a proper temperature, at which the seed reached thermal equilibrium with the melt. After pulling a cylinder crystal with $\sim 10 \mathrm{~mm}$ in length, the seed was necked down till it was tapered off to a diameter of 1.0-1.5 $\mathrm{mm}$, then the melt was slightly cooled down for the shouldering process, during which, the pulling rate varied from 0.5 to 3.0 $\mathrm{mm} \mathrm{h}^{-1}$ and the rotation speed was kept between 15 to $20 \mathrm{rpm}$. After reaching a final diameter of about $30 \mathrm{~mm}$, the pulling rate was set at $0.5-1.0 \mathrm{~mm} \mathrm{~h}^{-1}$ with a rotation rate of $16 \mathrm{rpm}$ for the crystal growth. After growth, the crystal was cooled down to room temperature at a rate of $15-35{ }^{\circ} \mathrm{C} \mathrm{h}^{-1}$ to reduce the thermal stress and to avoid cracks in the grown crystals.

Fig. 1(a) and (b) present the photographs of as-grown PrCOB single crystals pulled along the $<010>$ direction, in which the habitual faces $(-201)$ and (101) can be observed. Fig. 1(a) shows the PrCOB crystal with inclusions, induced by the improper thermal gradient distribution, leading to the supercooling of the melt. In addition, the inhomogeneous melt may also give rise to the inclusions in the grown crystals. After thermal profile modification (thermal gradient and growth speed), high quality single crystals (Fig. 1(b)) free of cracks and inclusions can be obtained.

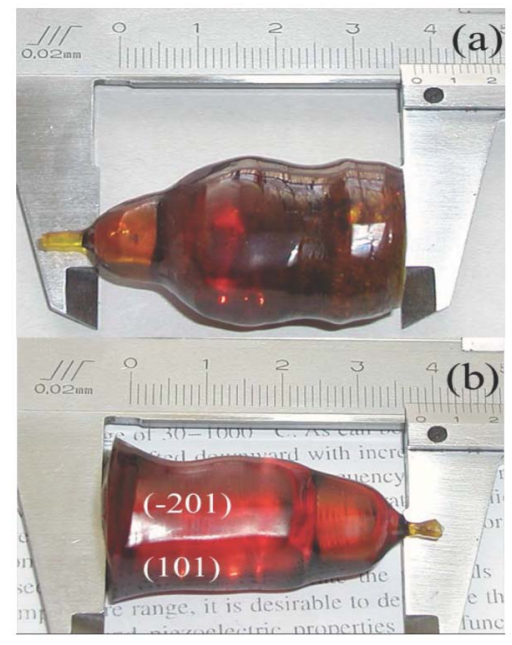

Fig. 1 PrCOB crystals pulling along the $<010>$ direction (a) PrCOB crystal with cracks and inclusions (b) PrCOB single crystal free of cracks and inclusions.

\section{Experimental}

Phase identification of the as-grown PrCOB crystals were performed by X-ray powder diffraction (XRPD) with a D8 Advance diffractometer (Bruker AXS, Advanced X-ray Solutions) using $\mathrm{Cu} \mathrm{K} \alpha$ radiation $(\lambda=1.5406 \AA)$ and graphite monochromator, at room temperature over a $2 \theta$ range of $10^{\circ}$ to $60^{\circ}$. The crystal structure was determined using a Bruker APEX2 CCD area-detector diffractometer with graphite monochromated Mo $\mathrm{K} \alpha$ radiation $(\lambda=0.71073 \AA)$.

The crystal density was obtained by two methods. The theoretical density, $\rho_{x}$, was calculated using the lattice parameters determined from a four circle X-ray diffractometer, following equation: $\rho_{x}=M Z /\left(a b c \sin \beta N_{\mathrm{A}}\right)$, where $M$ is the molar weight of the crystal, $N_{\mathrm{A}}$ is Avogadro's constant, $Z$ is the number of molecules in one unit cell, which is two for PrCOB crystal, $a, b$ and $c$ are the lattice parameters obtained by the $\mathrm{X}$-ray diffraction. For comparison, the experimental density, $\rho_{\mathrm{e}}$, was determined by the Archimedes method.

Thermal expansion behavior of PrCOB crystal was measured in the temperature range of 25 to $500{ }^{\circ} \mathrm{C}$ using a thermal dilatometer (Diamond TMA, Perkin-Elmer) with a heating rate of $5{ }^{\circ} \mathrm{C} \mathrm{min}^{-1}$. Specific heat was measured by differential scanning calorimeter using a simultaneous thermal analyzer (Diamond DSC, PerkinElmer) in the temperature range between 20 to $300{ }^{\circ} \mathrm{C}$, at a constant heating rate of $5{ }^{\circ} \mathrm{C} \mathrm{min}^{-1}$. The values of the specific heat were calculated by the supplied software (Perkin-Elmer Co.). The thermal diffusion coefficient and thermal conductivity of PrCOB crystal were measured using a Netzsch Nanoflash model LFA 457 apparatus along the crystallographic $b$ axis (physical $Y$ axis), by the laser pulse method in the temperature range of 20 to $700{ }^{\circ} \mathrm{C}$. During the measurement, square wafers $\left[4.00 \times 4.00 \times 1.20 \mathrm{~mm}^{3}(X \times Z \times Y)\right]$ were coated with graphite on opposite faces, the front surface of the wafer was heated by a laser pulse (the laser voltage was $1826 \mathrm{~V}$ and pulse width was $0.5 \mathrm{~ms}$ ), and the temperature rise versus time on the opposite surface was measured using an InSb IR detector. The thermal diffusion coefficients and thermal conductivity values were then calculated using the analytical software provided (Netzsch Co.).

\section{Results and discussions}

\section{Crystal structure}

Crystal phase of PrCOB single crystals were determined by XRPD, results are shown in Fig. 2, where strong diffraction peaks were observed for (220), (150), (-201), (240), (060) and (170) planes, with diffraction angles $(2 \theta)$ being $24.778^{\circ}$, $29.787^{\circ}, 30.091^{\circ}, 31.418^{\circ}, 33.244^{\circ}$ and $40.643^{\circ}$, respectively. Compared to XRPD patterns of ReCOB single crystals, PrCOB was found to show similar diffraction peaks as YCOB, GdCOB and NdCOB etc. Based on XRPD and the four-circle diffractometer measurement, PrCOB was found to possess space group $C m(Z=2)$, with cell parameters $a=8.177 \AA$, $b=16.157 \AA$, $c=3.629 \AA$ and $\beta=101.40^{\circ}$, slightly higher than NdCOB (PCPDF Card 04-009-2919: $a=8.145 \AA$, $b=16.06 \AA$, $c=3.607 \AA$ and $\left.\beta=101.37^{\circ}\right)$, though the rare-earth ionic radius for $\mathrm{Nd}^{3+}$ and $\operatorname{Pr}^{3+}$ are very close $\left(r^{\mathrm{Nd}^{3+}}=0.983 \AA\right.$ and $r^{\mathrm{Pr}^{3+}}=0.990 \AA$ (ref. 23)). 


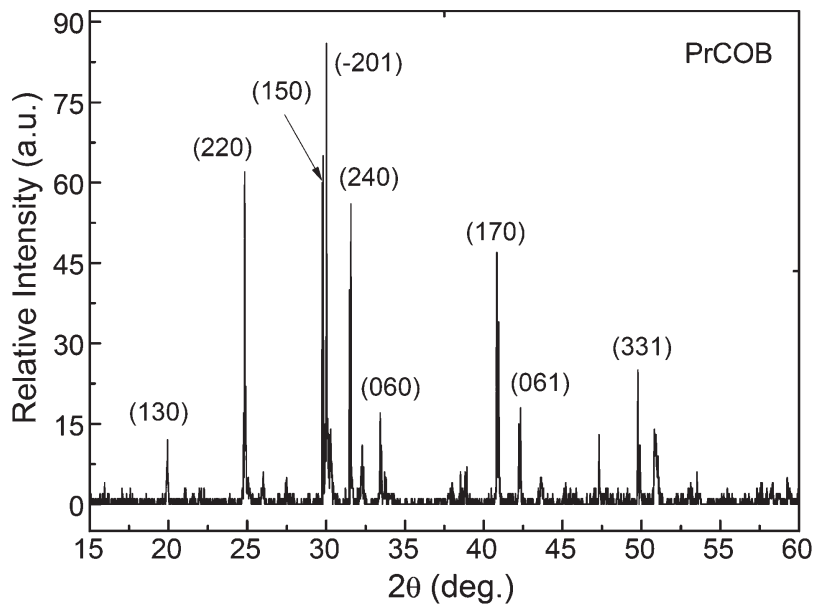

Fig. 2 XRPD characterization for PrCOB single crystals.

The structure building unit was considered to consist of five oxygen octahedra linked to three borate groups (as shown in Fig. 3(A)). In the structure unit, there is one distorted octahedron around the $\mathrm{Pr}$ atom, two different distorted octahedral positions for $\mathrm{Ca}$ atoms, which can be categorized as a $\mathrm{Pr}-\mathrm{O}$ octahedron and $\mathrm{Ca}(1)-\mathrm{O}$ and $\mathrm{Ca}(2)-\mathrm{O}$ octahedra. Fig. 3(B) gives the $\mathrm{Pr}-\mathrm{O}$ and $\mathrm{Ca}-\mathrm{O}$ octahedra and their typical bond lengths and bond angles, where the diagonal distance of O4-O4 in the Pr-O octahedron was found to be parallel to the crystallographic axis $b$. The average bond length of the Pr-O octahedron was calculated and found to be shorter than the $\mathrm{Ca}(1)-\mathrm{O}$ octahedron, but longer than those of $\mathrm{Ca}(2)-\mathrm{O}$ octahedron. In addition, there are two kinds of boron site, $\mathrm{B}(1)$ and $\mathrm{B}(2)$, observed in the PrCOB structure. The boron atoms in the PrCOB structure form planar orthoborate groups, where the B-O distance was found to range from 1.3712 to $1.3976 \AA$, with the standard deviation being on the order of $1.12 \%$.

\section{Crystal density}

Based on the crystal structure data $(a=8.177 \AA$, $b=16.157 \AA, c$ $=3.629 \AA$ and $\beta=101.40^{\circ}$ ), theoretical crystal density was calculated to be $\rho_{x}=\sim 3.49 \mathrm{~g} \mathrm{~cm}^{-3}$. For comparison, crystal

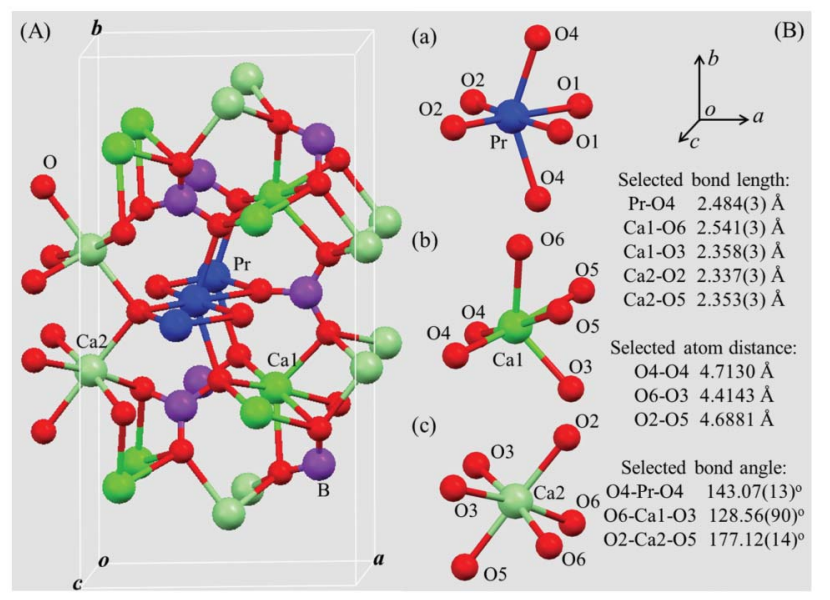

Fig. 3 Fragment of the PrCOB crystal structure and its Pr-O and Ca-O octahedra. density was measured using Archimedes method, the average experimental density was obtained and found to be $\rho_{\mathrm{e}}=\sim 3.47$ $\mathrm{g} \mathrm{cm}^{-3}$, slightly lower than the theoretical calculated value.

\section{Thermal expansion}

For crystals with a monoclinic phase, there are four independent thermal expansion coefficients $\left(\alpha_{11}, \alpha_{22}, \alpha_{33}\right.$ and $\left.\alpha_{13}\right)$. In the principal coordinate system, the $\left[\alpha_{i j}\right]$ tensor is diagonal,

$$
\left(\begin{array}{ccc}
\alpha_{11} & 0 & \alpha_{13} \\
0 & \alpha_{22} & 0 \\
\alpha_{13} & 0 & \alpha_{33}
\end{array}\right)
$$

among which, $\alpha_{11}, \alpha_{22}, \alpha_{33}$ can be obtained by measuring the thermal expansion along physical $X$-, $Y$-, $Z$-axes, according to the IEEE standard on piezoelectricity, ${ }^{24}$ while for $\alpha_{13}$, rotated cut crystal can be used, which has been discussed in previous work (the $\alpha_{13}$ value is small $\left(<1.0 \mathrm{ppm}{ }^{\circ} \mathrm{C}^{-1}\right)$, so it is neglectable). ${ }^{25}$ Fig. 4 gives the thermal expansion curves along physical $X$-, $Y$ - and $Z$-axes as a function of temperature for PrCOB. After calculation, the thermal expansion coefficients were determined to be $\alpha_{11}=7.99, \alpha_{22}=4.90$ and $\alpha_{33}=9.46$ $\left(10^{-6} /{ }^{\circ} \mathrm{C}\right)$, respectively. In addition, the variation of crystal density as a function of temperature was calculated based on the thermal expansion, and temperature coefficients of crystal density were obtained, where the first $\left(T \rho^{(1)}\right)$, second $\left(T \rho^{(2)}\right)$ and third $\left(T \rho^{(3)}\right)$ order of temperature coefficient were found to be $T \rho^{(1)}=-1.61 \times 10^{-5}{ }^{\circ} \mathrm{C}$, $T \rho^{(2)}=-2.60 \times 10^{-8}{ }^{\circ} \mathrm{C}^{2}$ and $T \rho^{(3)}=4.77 \times 10^{-11}{ }^{\circ} \mathrm{C}^{3}$, respectively.

\section{Specific heat}

The specific heat of the crystalline solids was generally described by the Debye lattice theory in terms of the harmonic frequency spectrum. However, due to the complex structure of the PrCOB crystal, it is hard to explain the measured specific heat with the predictions of the lattice theory. The dependence of the specific heat $\left(C_{\mathrm{p}}\right)$ of PrCOB with temperature is shown in Fig. 5, from which, it can be seen that the PrCOB crystal has a specific heat value of $0.63 \mathrm{~J} \mathrm{~g}^{-1}{ }^{\circ} \mathrm{C}^{-1}$ at $20{ }^{\circ} \mathrm{C}$, that increases linearly with increasing temperature. For comparison, the specific heat as a function of temperature for the ErCOB crystal was also measured and given in the inset of Fig. 5, where the

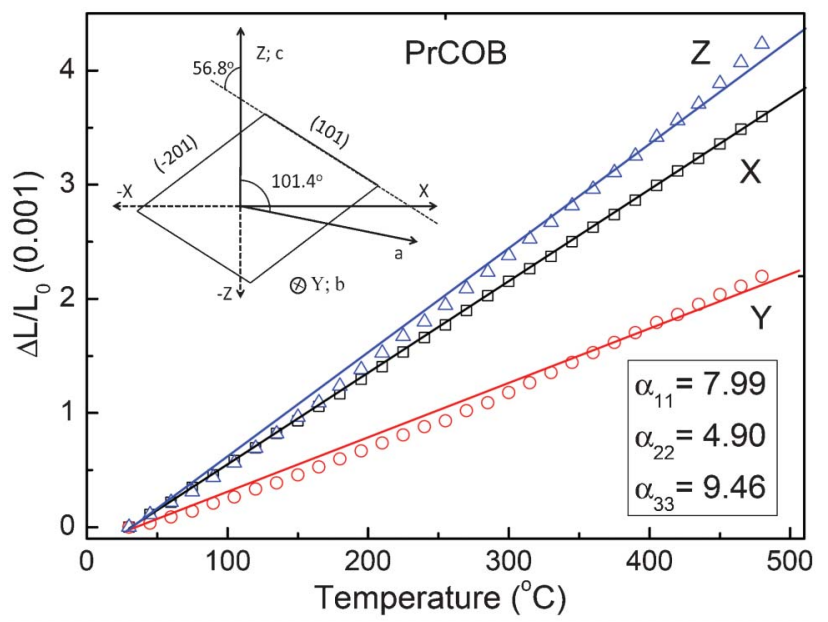

Fig. 4 Thermal expansion measurement of $\operatorname{PrCOB}$ crystal along $X, Y$ and $Z$ axes (inset is the schematic of physical axes and crystallographic axes, after ref. 15). 


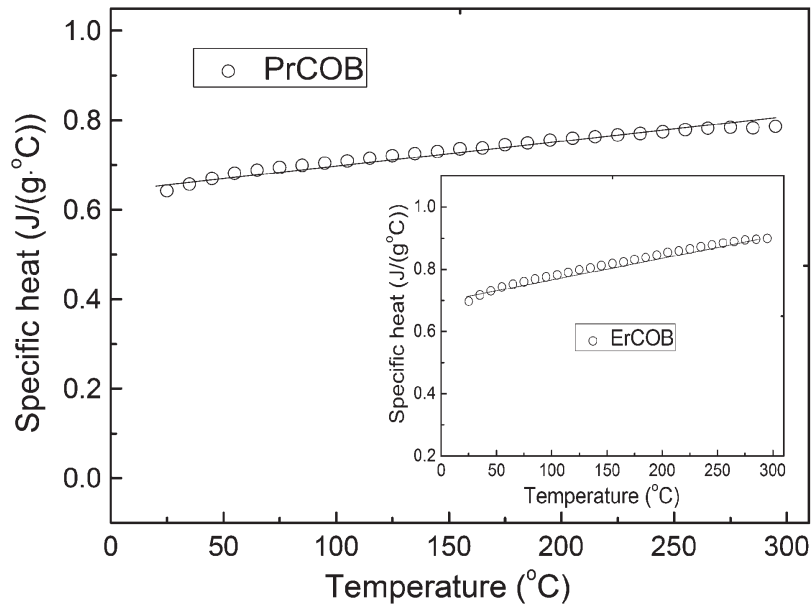

Fig. 5 Specific heat of the PrCOB crystal as a function of temperature, with ErCOB in the inset for comparison.

specific heat at room temperature was found to be $0.71 \mathrm{~J} \mathrm{~g}^{-1}$ ${ }^{\circ} \mathrm{C}^{-1}$, slightly higher than that of PrCOB, but similar to that of YCOB $\left.\left(0.73 \mathrm{~J} \mathrm{~g}^{-1}{ }^{\circ} \mathrm{C}^{-1}\right)\right)$. Table 1 lists the specific heat values for various ReCOB crystals, at room temperature and $300{ }^{\circ} \mathrm{C}$.

\section{Thermal diffusivity and thermal conductivity}

Thermal diffusivity $(\lambda)$ and thermal conductivity $(\kappa)$ are anisotropic and can be expressed by a second order tensor, similar to the thermal expansion coefficients. The thermal conductivity $\kappa$ can be obtained by measuring the specific heat $C_{\mathrm{p}}$ and thermal diffusivity $\lambda$, according to equation below,

$$
\kappa=\lambda \rho C_{\mathrm{p}}
$$

In this work, thermal conductivity $(\kappa)$ and thermal diffusivity $(\lambda)$ of PrCOB crystals were measured along the crystallographic axis $b$. Fig. 6 shows the variation of thermal conductivity and thermal diffusivity of PrCOB crystals in the temperature range of $20-700{ }^{\circ} \mathrm{C}$. In addition, the related specific heats at elevated temperatures obtained by laser pulsed method are also presented. It was found that the specific heat was slightly increased with increasing temperature, this is consistent with that obtained by differential scanning calorimeter, where the room temperature specific heat was determined to be $\sim 0.63 \mathrm{~J}$ $\mathrm{g}^{-1}{ }^{\circ} \mathrm{C}^{-1}$. In contrast to the specific heat, the thermal diffusivity $\lambda$ was found to decrease with increasing temperature, with

Table 1 Specific heat $C_{p}$ of ReCOB crystals at selected temperatures

\begin{tabular}{|c|c|c|}
\hline \multirow[b]{2}{*}{ Crystals } & \multicolumn{2}{|l|}{$C_{\mathrm{p}}$ values } \\
\hline & Room temperature & $300{ }^{\circ} \mathrm{C}$ \\
\hline ErCOB & 0.71 & 0.91 \\
\hline YCOB & 0.73 & 0.89 \\
\hline $\mathrm{GdCOB}^{26}$ & 0.60 & 0.77 \\
\hline SmCOB & 0.56 & 0.74 \\
\hline $\mathrm{NdCOB}^{25}$ & 0.55 & 0.89 \\
\hline PrCOB & 0.63 & 0.86 \\
\hline $\mathrm{LaCOB}^{8}$ & 0.63 & 0.74 \\
\hline
\end{tabular}

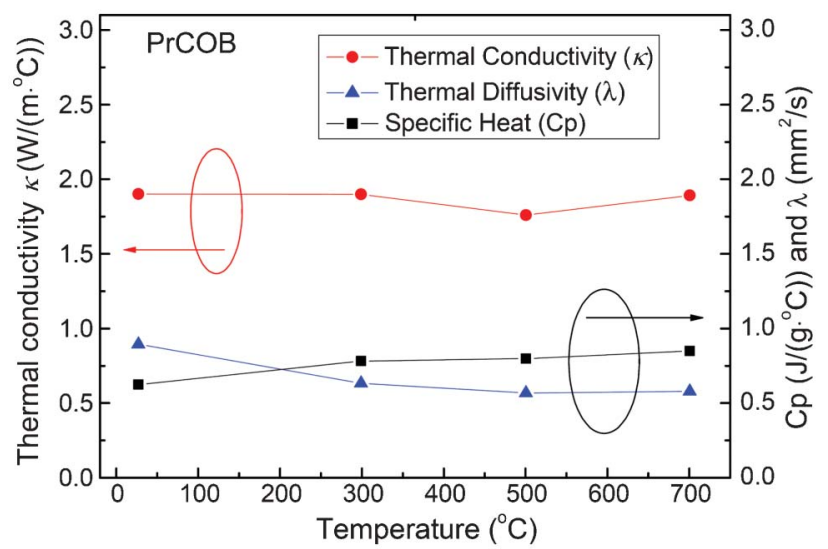

Fig. 6 Thermal conductivity and thermal diffusivity of the PrCOB crystal as a function of temperature.

values being on the order of $0.89 \mathrm{~mm}^{2} \mathrm{~s}^{-1}$ and $0.58 \mathrm{~mm}^{2} \mathrm{~s}^{-1}$ at room temperature and $700{ }^{\circ} \mathrm{C}$, respectively. Of particular importance is that the thermal conductivity $\kappa$ of PrCOB crystal was found to maintain the same value, being on the order of $\sim 1.90 \mathrm{~W} \mathrm{~m}^{-1}{ }^{\circ} \mathrm{C}^{-1}$ over the studied temperature range.

For better understanding the thermal behavior, YCOB and ErCOB single crystals were also investigated for comparison. The specific heat, thermal diffusivity and thermal conductivity were measured from 20 to $700{ }^{\circ} \mathrm{C}$, results are shown in Fig 7. It can be observed that the specific heat of YCOB crystal increased with increasing temperature, ranging from 0.73 to $1.13 \mathrm{~J} \mathrm{~g}^{-1}{ }^{\circ} \mathrm{C}^{-1}$, while the thermal diffusivity $\lambda$ firstly decreased with increasing temperature, exhibiting a turnover point at 600 ${ }^{\circ} \mathrm{C}\left(0.65 \mathrm{~mm}^{2} \mathrm{~s}^{-1}\right)$, then slightly increased with increasing temperature. Correspondingly, the thermal conductivity $\kappa$ was found to change from 2.79 at $20{ }^{\circ} \mathrm{C}$ to $2.05 \mathrm{~W} \mathrm{~m}^{-1}{ }^{\circ} \mathrm{C}^{-1}$ at 700 ${ }^{\circ} \mathrm{C}$, with the minimum $\kappa$ value $\sim 1.98 \mathrm{~W} \mathrm{~m}^{-1}{ }^{\circ} \mathrm{C}^{-1}$ occurred at $600{ }^{\circ} \mathrm{C}$. However, the ErCOB crystal was found to exhibit a similar trend to PrCOB, where the thermal conductivity $\kappa$ was found to maintain the same value, being around $\sim 2.00 \mathrm{~W} \mathrm{~m}^{-1}$ ${ }^{\circ} \mathrm{C}^{-1}$ in the same temperature range.

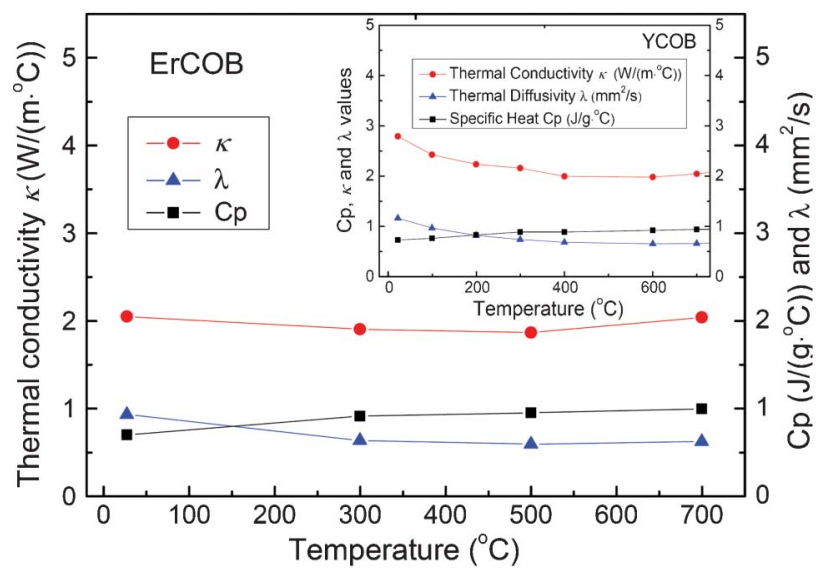

Fig. 7 Thermal conductivity and thermal diffusivity of ErCOB and YCOB crystal as a function of temperature. 
It is known that heat transfer occurs in solid by means of free electron diffusion and lattice wave, where the lattice wave plays an important role for thermal conduction in insulators, especially for the case of ReCOB crystals, due to their high resistivity $\left(\rho>10^{14} \Omega\right.$ $\mathrm{cm}$ at room temperature). ${ }^{21}$ The thermal conduction induced by a lattice wave can be regarded as a phonon scattering effect, relating to the phonon mean free path. According to the Debye mode, the thermal conductivity can be expressed as:

$$
\kappa=1 / 3 C_{\mathrm{v}} l v
$$

where $l$ is the phonon mean free path, $C_{\mathrm{v}}$ is the specific heat at constant volume and $v$ is the average sound velocity, which is considered as constant. ${ }^{27}$ The variation of thermal conductivity as a function of temperature is related to the temperature dependent phonon mean free path and specific heat. ${ }^{28}$ Thus, the less variation of the thermal conductivity for ErCOB and PrCOB crystals indicates the independence of the phonon mean free path over the temperature range, while the decrease of the thermal conductivity of YCOB crystal in the temperature range of $20-600{ }^{\circ} \mathrm{C}$ indicates the decrease of phonon mean free path, accounting for phonon scattering at elevated temperatures, associated with crystal defects. However, it should be noted that the thermal conductivity $\kappa$ of YCOB is higher than that of PrCOB, both at room temperature and elevated temperatures, demonstrating that the phonon mean free path for the YCOB crystal is longer than that of the PrCOB crystal, associates with the lower level of phonon scattering, and accounts for higher mechanical quality factor and resistivity in YCOB crystals. This phenomenon was consistent with the discussion in previous research. ${ }^{20}$

\section{Conclusions}

PrCOB single crystals were grown by the Czochralski pulling method, crystal structure and thermal properties were investigated. The crystal structure of the PrCOB crystal was determined to be monoclinic phase (space group $\mathrm{Cm}$ ), with unit cell parameters $a$ $=8.177 \AA, b=16.157 \AA, c=3.629 \AA$ and $Z=2$. The crystal density at room temperature was measured to be $3.47 \mathrm{~g} \mathrm{~cm}^{-3}$ and the density temperature coefficients were: $T \rho^{(1)}=-1.61 \times 10^{-5}{ }^{\circ} \mathrm{C}$, $T \rho^{(2)}=-2.60 \times 10^{-8}{ }^{\circ} \mathrm{C}^{2}$ and $T \rho^{(3)}=4.77 \times 10^{-11}{ }^{\circ} \mathrm{C}^{3}$, respectively. The thermal expansion coefficients along the physical axes $X, Y$ and $Z$ were investigated and found to be on the order of $\alpha_{11}=7.99$, $\alpha_{22}=4.90$ and $\alpha_{33}=9.46\left(10^{-6} /{ }^{\circ} \mathrm{C}\right)$, respectively.

The specific heat, thermal diffusivity and thermal conductivity for PrCOB crystals were studied in the temperature range of $20-700^{\circ} \mathrm{C}$, where the specific heat was found to increase from $0.63 \mathrm{~J} \mathrm{~g}^{-1}{ }^{\circ} \mathrm{C}^{-1}$ at room temperature to $0.85 \mathrm{~J} \mathrm{~g}^{-1}{ }^{\circ} \mathrm{C}^{-1}$ at $700{ }^{\circ} \mathrm{C}$. However, the thermal diffusivity was observed to decrease with increasing temperature, with $\lambda_{22}$ being on the order of $0.89 \mathrm{~mm}^{2}$ $\mathrm{s}^{-1}$ at room temperature and $0.58 \mathrm{~mm}^{2} \mathrm{~s}^{-1}$ at $700{ }^{\circ} \mathrm{C}$. The increase of specific heat $C_{\mathrm{p}}$ and decrease of thermal diffusivity $\lambda_{22}$ with increasing temperature were observed for PrCOB, ErCOB and YCOB crystals. However, different trends were found for thermal conductivity $\kappa_{22}$, where the $\kappa_{22}$ value of the YСOB crystal decreased from 2.79 to $2.05 \mathrm{~W} \mathrm{~m}^{-1}{ }^{\circ} \mathrm{C}^{-1}$, while $\operatorname{PrCOB}$ and ErCOB maintained the same value, being $\sim 1.90$ and $\sim 2.00$ $\mathrm{W} \mathrm{m}{ }^{-1}{ }^{\circ} \mathrm{C}^{-1}$ over the studied temperature range, respectively.

\section{Appendices}

Table 2 Crystal data and structure refinement for PrCOB crystals

Crystal system, space group

Volume

$Z$, calculated density

Absorption coefficient

$F(000)$

Crystal size

Theta range for data collection

Limiting indices

Reflections collected/unique Completeness to theta $=27.45$ Absorption correction

Max. and min. transmission

Refinement method

Data/restraints/parameters

Goodness-of-fit on $F^{2}$

Final $R$ indices $[I>2 \operatorname{sigma}(I)]$

$R$ indices (all data)

Absolute structure parameter

Extinction coefficient

Largest diff. peak and hole
Unit cell dimensions

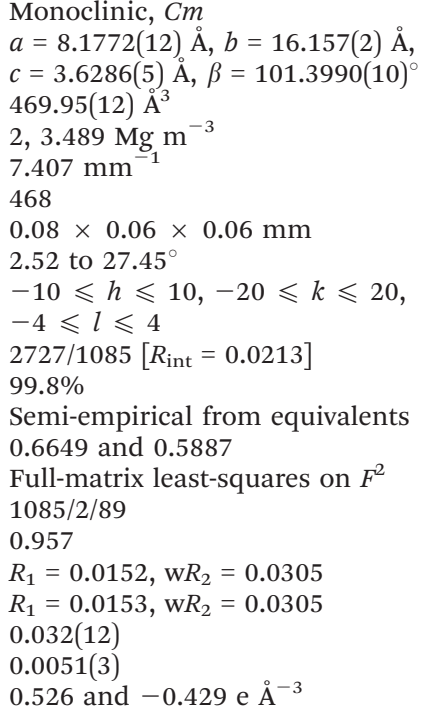

Table 3 Atomic coordinates $\left(\times 10^{4}\right)$ and equivalent isotropic displacement parameters $\left(\AA^{2} \times 10^{3}\right)$ for PrCOB. $U_{\text {eq }}$ is defined as one third of the trace of the orthogonalized $U_{i j}$ tensor

\begin{tabular}{lllll}
\hline Atom & $x$ & $y$ & $z$ & $U_{\text {eq }}$ \\
\hline $\mathrm{Pr}$ & $3593(1)$ & 5000 & $1535(1)$ & $8(1)$ \\
$\mathrm{Ca}(1)$ & $6284(1)$ & $3187(1)$ & $-1839(2)$ & $10(1)$ \\
$\mathrm{Ca}(2)$ & $41(1)$ & $3863(1)$ & $4858(2)$ & $7(1)$ \\
$\mathrm{O}(1)$ & $5686(6)$ & 5000 & $-2363(14)$ & $14(1)$ \\
$\mathrm{O}(2)$ & $1843(6)$ & 5000 & $5679(13)$ & $6(1)$ \\
$\mathrm{O}(3)$ & $8276(3)$ & $5739(2)$ & $-899(7)$ & $11(1)$ \\
$\mathrm{O}(4)$ & $4554(3)$ & $3542(2)$ & $2405(8)$ & $11(1)$ \\
$\mathrm{O}(5)$ & $3290(3)$ & $2304(2)$ & $4338(7)$ & $13(1)$ \\
$\mathrm{O}(6)$ & $6613(3)$ & $1699(2)$ & $449(7)$ & $12(1)$ \\
$\mathrm{B}(1)$ & $3146(5)$ & $3057(3)$ & $2408(12)$ & $7(1)$ \\
$\mathrm{B}(2)$ & $7427(7)$ & 5000 & $-1379(16)$ & $8(1)$ \\
\hline
\end{tabular}

Table 4 Anisotropic displacement parameters $\left(\AA^{2} \times 10^{3}\right)$ for PrCOB single crystals. The anisotropic displacement factor exponent takes the form: $-2 \pi^{2}\left[\left(h^{2} a^{*}\right)^{2} U_{11}+\cdots+2 h k a^{*} b^{*} U_{12}\right]$

\begin{tabular}{lllllll}
\hline Atom & $U_{11}$ & $U_{22}$ & $U_{33}$ & $U_{23}$ & $U_{13}$ & $U_{12}$ \\
\hline $\mathrm{Pr}$ & $7(1)$ & $14(1)$ & $5(1)$ & 0 & $1(1)$ & 0 \\
$\mathrm{Ca}(1)$ & $10(1)$ & $13(1)$ & $7(1)$ & $1(1)$ & $2(1)$ & $1(1)$ \\
$\mathrm{Ca}(2)$ & $7(1)$ & $7(1)$ & $6(1)$ & $0(1)$ & $1(1)$ & $0(1)$ \\
$\mathrm{O}(1)$ & $5(2)$ & $30(3)$ & $8(2)$ & 0 & $4(2)$ & 0 \\
$\mathrm{O}(2)$ & $4(2)$ & $4(2)$ & $8(2)$ & 0 & $-1(2)$ & 0 \\
$\mathrm{O}(3)$ & $13(1)$ & $8(1)$ & $13(1)$ & $1(1)$ & $2(1)$ & $-4(1)$ \\
$\mathrm{O}(4)$ & $11(2)$ & $11(1)$ & $12(1)$ & $0(1)$ & $3(1)$ & $-2(1)$ \\
$\mathrm{O}(5)$ & $17(1)$ & $10(1)$ & $15(1)$ & $6(1)$ & $8(1)$ & $3(1)$ \\
$\mathrm{O}(6)$ & $10(2)$ & $16(2)$ & $9(1)$ & $0(1)$ & $1(1)$ & $-6(1)$ \\
$\mathrm{B}(1)$ & $10(2)$ & $7(2)$ & $5(2)$ & $-4(2)$ & $2(2)$ & $1(2)$ \\
$\mathrm{B}(2)$ & $3(3)$ & $17(3)$ & $4(3)$ & 0 & $1(2)$ & 0 \\
& & & & & & \\
\hline
\end{tabular}

\section{Acknowledgements}

This work was financially supported by the National Natural Science Foundation of China (Grant Nos. 91022034, 
51202129), the grant from the Impact and Safety of Coastal Engineering Initiative, a COE Program of Zhejiang Provincial Government at Ningbo University (Grant No. ZJ1111), the Independent Innovation Foundation of Shandong University (IIFSDU) and China Postdoctoral Science Foundation.

\section{Notes and references}

1 S. J. Zhang, J. G. Zhang, Z. X. Cheng, G. Y. Zhou, J. R. Han and H. C. Chen, J. Cryst. Growth, 1999, 203, 168.

2 Y. T. Fei, B. H. T. Chai, C. A. Ebbers, Z. M. Liao, K. I. Schaffers and P. Thelin, J. Cryst. Growth, 2006, 290, 301.

3 G. Aka, F. Salin and D. Pelenc, J. Opt. Soc. Am. B, 1997, 14, 2238.

4 W. W. Ge, H. J. Zhang, J. Y. Wang, M. H. Jiang, S. Q. Sun, D. G. Ran, H. R. Xia and R. I. Boughton, J. Appl. Crystallogr., 2007, 40, 125.

5 S. J. Zhang, Z. X. Cheng, J. H. Lu, G. M. Li, J. R. Lu, Z. S. Shao and H. C. Chen, J. Cryst. Growth, 1999, 205, 453.

6 S. J. Zhang, Z. X. Cheng, S. J. Zhang, J. R. Han, L. K. Sun and H. C. Chen, J. Cryst. Growth, 2000, 213, 415.

7 H. J. Zhang, H. D. Jiang, J. Y. Wang, X. B. Hu, G. W. Yu, W. T. Yu, L. Gao, J. A. Liu, S. J. Zhang and M. H. Jiang, Appl. Phys. A: Mater. Sci. Process., 2004, 78, 889.

8 S. J. Zhang and F. P. Yu, J. Am. Ceram. Soc., 2011, 94, 3153.

9 J. Y. Wang, X. B. Hu, X. Yin, R. B. Song, J. Q. Wei, Z. S. Shao, Y. G. Liu, M. H. Jiang, Y. L. Tian, J. H. Jiang and W. X. Huang, J. Mater. Res., 2001, 16, 790.

10 H. Takeda, H. Sako, H. Shimizu, K. Kodama, M. Nishida, H. Nakao, T. Nishida, S. Okamura and T. Shikida, Jpn. J. Appl. Phys., 2003, 42, 6081.

11 H. Shimizu, T. Nishida, M. Nishida, H. Takeda and T. Shiosaki, Jpn. J. Appl. Phys., 2005, 44, 7059.

12 H. Shimizu, H. Takeda, T. Nishida, S. Okamura, T. Shiosaki and T. Shikida, Proc. - IEEE Ultrason. Symp., 2004, 1218-1222.
13 C. Pawlaczyk, E. Markiewicz, A. Klos, W. Hofman and A. Pajaczkowska, Phys. Status Solidi A, 2006, 203, 2103.

14 S. J. Zhang, Y. T. Fei, B. H. T. Chai, E. Frantz, D. W. Snyder, X. N. Jiang and T. R. Shrout, Appl. Phys. Lett., 2008, 92, 202905.

15 S. J. Zhang, E. Frantz, R. Xia, W. Everson, J. Randi, D. W. Snyder and T. R. Shrout, J. Appl. Phys., 2008, 104, 084103.

16 H. Nakao, M. Nishida, T. Shikida, H. Shimizu, H. Takeda and T. Shiosaki, J. Alloys Compd., 2006, 408, 582.

17 S. J. Zhang, X. N. Jiang, M. Lapsley, M. Paul and T. R. Shrout, Appl. Phys. Lett., 2010, 96, 013506.

18 K. Kim, S. J. Zhang, G. Salazar and X. N. Jiang, Sens. Actuators, A, 2012, 178, 40.

19 K. Kim, S. J. Zhang, W. B. Huang, F. P. Yu and X. N. Jiang, J. Appl. Phys., 2011, 109, 126103.

20 F. P. Yu, S. J. Zhang, X. Zhao, S. Y. Guo, X. L. Duan, D. R. Yuan and T. R. Shrout, J. Phys. D: Appl. Phys., 2011, 44, 135405.

21 T. R. Shrout, F. P. Yu, S. J. Zhang, Q. M. Wang, Y. T. Fei and B. H. T. Chai, Joint Conference of the IEEE International Frequency Control and the European Frequency and Time Forum, 2011, 1-4.

22 F. P. Yu, S. J. Zhang, X. Zhao, D. R. Yuan, L. F. Qin, Q. M. Wang and T. R. Shrout, IEEE Trans. Ultrason. Ferroelectr. Freq. Control, 2011, 58, 868.

23 R. D. Shannon, Acta Crystallogr., Sect. A: Cryst. Phys., Diffr., Theor. Gen. Crystallogr., 1976, 32, 751.

24 IEEE Standard on Piezoelectricity, ANSI/IEEE Standards, 1987, 176, 15.

25 F. P. Yu, S. J. Zhang, X. Zhao, D. R. Yuan, C. M. Wang and T. R. Shrout, Cryst. Growth Des., 2010, 10, 1871.

26 M. Frédéric, K. H. Andrée, A. Gérard and P. Denis, J. Mater. Chem., 1998, 8, 1619.

27 C. L. Choy, W. P. Leung, T. G. Xi, Y. Fei and C. F. Shao, J. Appl. Phys., 1992, 71, 170.

28 C. Kittel, Phys. Rev., 1949, 75, 972. 